\title{
Fighting Cancer Stem Cells Via Armored Mesenchymal Stem Cells with Napabucasin: A New Strategy for Cancer Therapy
}

\author{
Mohammad Kamalabadi Farahani* \\ Department of Tissue Engineering, School of Medicine, Shahroud University of Medical Sciences, Iran
}

Submission: July 17, 2019; Published: August 21, 2019

"Correspondence Author: Mohammad Kamalabadi Farahani, Department of Tissue Engineering, School of Medicine, Shahroud University of Medical Sciences and Health Services, Iran

\begin{abstract}
Cancer relapse and metastasis are associated with part of cancer cells with stem cell properties. These cancer stem cells are resistant to current treatment of cancer, such as chemotherapy and radiation therapy. Stem cell biologists hypothesized that inhibition of cancer stemness can effectively suppress metastasis and relapse. BBI608 (Napabucasin) is a small molecule which inhibits Stat3 cell signaling pathway and cancer stemness properties. This drug can block spherogenesis of cancer stem cell and kill them effectively. Recently rattle-type nanoparticles that are hollow nanospheres with mesoporous shells and metal cores are introduced for drug delivery. These types of the nanoparticle can effectively entrap small molecules and efficiently anchored to the surface of mesenchymal stem cells by specific antigen-antibody recognitions. Mesenchymal stem cells can track tumors and their micrometastasis after intravenous injection in the cancer animal models. We suggest that mesenchymal stem cells armored with entrapped Napabucasin in silica nanorattle can effectively track tumors and deliver Napabucasin to cancer stem cells to inhibit them and subsequently eradicate the tumor bulk. This protocol combined with current chemotherapeutic drugs can be employed for the treatment of cancer in particular metastatic cancer.
\end{abstract}

Keywords: Cancer Stem Cells; Napabucasin; Drug Delivery; Mesenchymal stem cells

\section{Background}

In the second half of the twentieth century by eliminating and controlling infectious agents, improving health system as well as changes in lifestyle and eating pattern, chronic noncommunicable diseases, has found as a major problem in the industrialized world. One of the most important of these diseases is cancer [1]. Common treatments for cancer can partially or even completely regress tumors in patients. Cancer cells are heterogeneous population, in which part of cancer cells have stemness properties and resistant to common chemotherapy and radiation treatment. Hence, scientists emphasize these cells are responsible for cancer relapse and metastasis [2]. BBI608 (Napabucasin) is a potent, broad-spectrum cancer cell stemness inhibitor that inhibits STAT3-driven gene transcription and prevents self-renewal in cancer stem cells [3]. Clinical trials are being conducted to take advantage of Napabucasin inhibitory potential against cancer stem cells. In various studies, Napabucasin has been used along with the common chemotherapeutic drug for the treatment of various cancers, such as NSCLC [4] and gastric cancer [5].
Mesoporous silica materials were discovered in 1992 by Mobile Oil Corporation [6]. These compounds are new promising carriers for drugs and their unique structure allows controlled release of a variety of drug molecules [7,8]. Like most drug delivery systems, targeted drug delivery to the tumor position is the main problem of silica nanoparticles [9]. This material after systemic administration enters into the bloodstream and rapidly collected by the reticuloendothelial system (RES) [10]. As a consequence, only a minor fraction of nanoparticles can finally be accumulated in tumor location which would be insufficient to exert a therapeutic effect [11]. Mesenchymal stem cells (MSCs) are multipotent stem cells that can be easily isolated and expanded from some adult and fetal tissues such as bone marrow, adipose tissue, placenta and umbilical cord [1214]. This type of stem cells has an innate ability to differentiate along multiple cell lineages, including osteogenic, chondrogenic and adipogenic lineages [15]. Apart from the important role of these cells in tissue regeneration [16,17], the ability of MSCs to migrate specifically to the tumor site has been demonstrated in different tumor animal models $[18,19]$. 


\section{Cancer Therapy \& Oncology International Journal}

\section{Presentation of the Hypothesis}

We suggest that mesenchymal stem cells armored with entrapped Napabucasin in silica nanorattle can effectively track tumors and deliver Napabucasin to cancer stem cells to inhibit them and subsequently eradicate the tumor bulk. This protocol combined with current chemotherapeutic drugs can be employed for the treatment of cancer in particular metastatic cancer.

\section{Experimental Design}

Experiments could be designed with developing an animal model of metastatic cancer. For this purpose, animal model of metastatic breast cancer can be developed in BALB/c mice with injections of the $4 \mathrm{~T} 1$ cell line in the mammary fat pad of female mice. After developing the animal model, MSCs can be obtained from fetal tissues such as umbilical cord, Wharton's jelly or placental tissues. MSCs must be characterized and expanded in a cell culture flask and loaded with nanorattle entrapping Napabucasin. Nanorattle must be loaded with BBI608 (Napabucasin) and bioconjugated with a monoclonal antibody for specifically binding with the MSCs' membrane proteins CD73 and CD90. Eventually, these armored cells are intravenously injected in developed mouse models and their effects on tumor size and other parameters must be measured. This protocol can be tested alone or in combination with intraperitoneal injection of one of the current chemotherapy drugs.

\section{Implications of the Hypothesis}

Mesenchymal stem cells can track tumors and their micrometastasis after intravenous injection in the cancer animal model. This ability has great importance when discussed metastatic tumors like breast tumors [20]. These cell types also have immunosuppressive properties and they can be used as allogeneic and even xenogeneic source of cells in cell therapy [21]. These properties make MSCs as the best candidate for targeted delivery of the antineoplastic agent to the tumor site that has been demonstrated in different studies [19-22]. Accordingly, MSCs from various origins are somehow genetically engineered to convey a particular therapeutic molecule such as IFN- $\beta$ [23], IFN- $\gamma$ [24], IL-12 [25], IL-24 [26], and TRIAL [27] After systemic administration in tumor animal models, these engineered cells successfully delivered therapeutic agents in tumor position. MSCs have also been employed to serve as vehicles for suicide gene/enzyme prodrug systems [28] and Oncolytic viruses [29]. In addition, some compounds loaded to MSCs with an intermediate nanoparticle. For example, silica nanorattle-doxorubicin anchored MSCs [30] and MSCs loaded with paclitaxel-containing nanoparticles [31] have been used in animal models of tumor successfully. Rattle-type nanoparticles that are hollow nanospheres with mesoporous shells and metal cores can effectively entrap small molecules and efficiently anchored to the surface of mesenchymal stem cells by specific antibody-antigen recognitions [30]. BBI608 (Napabucasin) is a small molecule that recently, its effects on inhibiting cancer stem cells has been demonstrated.

This small molecule shows antineoplastic and antimetastatic effects in vivo and clinical trials with this compound combined with routine chemotherapeutic drugs are in progress [32]. It seems similar to another antineoplastic drug side effect resulted from systemic administration of this drug, there is a major restriction for use of this drug. Thus, we suggest that targeted delivery of Napabucasin to tumor site can effectively inhibit cancer stem cell and eliminate them. With regard that Napabucasin is a small molecule, it seems it can be easily entrapped into nanoparticles. Then these nanoparticles will conjugate with antibody and easily loaded to MSCs. These armored MSCs transfers the Napabucasin to the site of the tumor after intravenous injection. This protocol combined with current chemotherapeutic drugs can be employed for the treatment of cancer in particular metastatic cancer.

\section{Concluding Remarks}

This hypothesis, design new method to specifically target CSCs and in combination with current anticancer drugs develop newer strategies in cancer therapy. This strategy may eradicate cancer relapse and metastasis and must be respected with oncologists to transition from bench to bedside for better cancer therapy.

\section{Conflict of Interest}

The author declares that they have no competing interests.

\section{References}

1. Organization WH. WHO, Global status report on noncommu-nicable diseases 2010, WHO Library Cataloguing-in-Publication Data pp. 162.

2. Dittmar T, Nagler C, Schwitalla S, Reith G, Niggemann B, et al. (2009) Recurrence cancer stem cells-made by cell fusion? Med Hypotheses 73(4): 542-547.

3. Li Y, Rogoff HA, Keates S, Gao Y, Murikipudi S, Mikule K, et al. (2015) Proc Natl Acad Sci U S A112(6): 1839-1844.

4. Becerra C, Spira AI, Conkling PR, Richey SL, Hanna WT, et al. (2016) A phase Ib/II study of cancer stemness inhibitor napabucasin (BB608) combined with weekly paclitaxel in advanced non-small cell lung cancer. American Society of Clinical Oncology, USA.

5. Shitara K, Kuboki Y, Nakamura Y, Doi A, Harada K, et al. (2015) A phase I study of BBI608, a cancer stemness inhibitor, administered with paclitaxel (PTX) as combination therapy (Rx) for pretreated unresectable or recurrent gastric cancer. American Society of Clinical Oncology, USA.

6. Kresge C, Leonowicz M, Roth W, Vartuli J, Beck J (1992) Ordered mesoporous molecular sieves synthesized by a liquid-crystal template mechanism. Nature 359(6397): 710-712.

7. Brannon-Peppas L (1995) Recent advances on the use of biodegradable microparticles and nanoparticles in controlled drug delivery International Journal of Pharmaceutics.116(1): 1-9.

8. Kwon S, Singh RK, Perez RA, Abou Neel EA, Kim HW et al. (2013) Silicabased mesoporous nanoparticles for controlled drug delivery. J Tissue Eng 3(4): 2041731413503357. 


\section{Cancer Therapy \& Oncology International Journal}

9. Jain RK, Stylianopoulos T (2010) Delivering nanomedicine to solid tumors. Nat Rev Clin Oncol 7(11): 653-654.

10. Torchilin V (2011) Tumor delivery of macromolecular drugs based on the EPR effect. Adv Drug Deliv Rev 63(3): 131-135.

11. Minchinton AI, Tannock IF (2006) Drug penetration in solid tumours. Nat Rev Cancer 6(8): 583-592.

12. Bieback K, Kern S, Kocaömer A, Ferlik K, Bugert P (2008) Comparing mesenchymal stromal cells from different human tissues: bone marrow, adipose tissue and umbilical cord blood. Biomed Mater Eng 18(s1): 71-76.

13. DiGirolamo CM, Stokes D, Colter D, Phinney DG, Class R, Prockop DJ (1999) Propagation and senescence of human marrow stromal cells in culture: a simple colony-forming assay identifies samples with the greatest potential to propagate and differentiate. $\mathrm{Br} \mathrm{J}$ Haemato 107(2): 275-281

14. Yen BL, Huang HI, Chien CC, Jui HY, Ko BS, et al. (2005) Isolation of multipotent cells from human term placenta. Stem cells. 23(1): 3-9.

15. Barry FP, Murphy JM (2004) Mesenchymal stem cells: clinical applications and biological characterization. Int J Biochem Cell Biol. 36(4): 568-584.

16. Wu Y, Chen L, Scott PG, Tredget EE (2007) Mesenchymal stem cells enhance wound healing through differentiation and angiogenesis. Stem cells 25(10): 2648-2659.

17. Wu Y, Wang J, Scott PG, Tredget EE (2007) Bone marrow-derived stem cells in wound healing: a review. Wound Repair Regen 15(s1): S18-S26.

18. Spaeth E, Klopp A, Dembinski J, Andreeff M, Marini F (2008) Inflammation and tumor microenvironments: defining the migratory itinerary of mesenchymal stem cells. Gene Ther 15(10): 730-738.

19. Dwyer RM, Khan S, Barry FP, O’Brien T, Kerin MJ (2010) Advances in mesenchymal stem cell-mediated gene therapy for cancer. Stem Cell Res Ther 1(3): 25.

20. Xie C, Yang Z, Suo Y, Chen Q, Wei D, et al. (2017) Systemically Infused Mesenchymal Stem Cells Show Different Homing Profiles in Healthy and Tumor Mouse Models. Stem Cells Translational Medicine. 6(4): $1120-1131$

21. Lin CS, Lin G, Lue TF (2012) Allogeneic and xenogeneic transplantation of adipose-derived stem cells in immunocompetent recipients without immunosuppressants. Stem Cells Dev 21(15): 2770-2778.
22. Baird S (2015) Mesenchymal stem cells: how can we realize their therapeutic potential in cancer therapy? Journal of Clinical \& Experimental Pathology 5: 206.

23. Dembinski JL, Wilson SM, Spaeth EL, Studeny M, Zompetta C, et al. (2013) Tumor stroma engraftment of gene-modified mesenchymal stem cells as anti-tumor therapy against ovarian cancer. Cytotherapy 15(1):20-32.

24. Yang X, Du J, Xu X, Xu C, Song W (2014) IFN- $\gamma$-secreting-mesenchymal stem cells exert an antitumor effect in vivo via the trail pathway. J Immunol Res 2014-318098.

25. Chen X, Lin X, Zhao J, Shi W, Zhang H, et al. (2008) A tumor-selective biotherapy with prolonged impact on established metastases based on cytokine gene-engineered MSCs. Mol Ther 16(4): 749-756.

26.Zhang X, Zhang L, Xu W, Qian H, Ye S, et al. (2013) Experimental therapy for lung cancer: umbilical cord-derived mesenchymal stem cell-mediated interleukin-24 delivery. Curr Cancer Drug Targets 13(1): 92-102.

27. Yuan Z, Kolluri KK, Gowers KH, Janes SM (2017) TRAIL delivery by MSC-derived extracellular vesicles is an effective anticancer therapy. Journal of extracellular vesicles 6(1): 1265291.

28. Uchibori R, Okada T, Ito T, Urabe M, Mizukami H, et al. (2009) Retroviral vector-producing mesenchymal stem cells for targeted suicide cancer gene therapy. J Gene Med 11(5): 373-381.

29. Yong RL, Shinojima N, Fueyo J, Gumin J, Vecil GG, Marini FC, et al (2009) Human bone marrow-derived mesenchymal stem cells for intravascular delivery of oncolytic adenovirus $\triangle 24-$ RGD to human gliomas. Cancer Res 69(23): 8932-8940.

30. Li L, Guan Y, Liu H, Hao N, Liu T, et al. (2011) Silica nanorattledoxorubicin-anchored mesenchymal stem cells for tumor-tropic therapy. ACS nano 5(9): 7462-7470.

31. Sadhukha T, O’Brien TD, Prabha S (2014) Nano-engineered mesenchymal stem cells as targeted therapeutic carriers. J Control Release 196: 243-251.

32. Hitron M, Stephenson J, Chi KN, Edenfield WJ, Leggett D, et al. (2014) A phase $1 \mathrm{~b}$ study of the cancer stem cell inhibitor BBI608 administered with paclitaxel in patients with advanced malignancies. American Society of Clinical Oncology, USA.

\section{Your next submission with Juniper Publishers will reach you the below assets}

- Quality Editorial service

- Swift Peer Review

- Reprints availability

- E-prints Service

- Manuscript Podcast for convenient understanding

- Global attainment for your research

- Manuscript accessibility in different formats

( Pdf, E-pub, Full Text, Audio)

- Unceasing customer service

Track the below URL for one-step submission

https://juniperpublishers.com/online-submission.php 